\title{
Characterization of highly virulent multidrug resistant Vibrio cholerae isolated from a large cholera outbreak in Ghana
}

\author{
Patrick Kwame Feglo* and Miriam Sewurah
}

\begin{abstract}
Objective: The purpose of this study was to investigate the virulent factors of Vibrio cholerae which caused an unprecedented large cholera outbreak in Ghana in 2014 and progressed into 2015, affected 28,975 people with 243 deaths.

Results: The V. cholerae isolates were identified to be the classical V. cholerae 01 biotype El Tor, serotype Ogawa, responsible for the large cholera outbreak in Ghana. These El Tor strains bear CtxAB and Tcp virulent genes, making the strains highly virulent. The strains also bear SXT transmissible element coding their resistance to antibiotics, causing high proportions of the strains to be multidrug resistant, with resistant proportions of 95, 90 and 75\% to trimethoprim/sulfamethoxazole, ampicillin and ceftriaxone respectively. PFGE patterns indicated that the isolates clustered together with the same pattern and showed clusters similar to strains circulating in DR Congo, Cameroun, Ivory Coast and Togo. The strains carried virulence genes which facilitated the disease causation and spread. This is the first time these virulent genes were determined on the Ghanaian Vibrio strains.
\end{abstract}

Keywords: Vibrio cholerae, CtxAb, Tcp, Antimicrobial resistance, SXT constin, PFGE

\section{Introduction}

Toxigenic Vibrio cholerae causes an acute diarrhoeal disease called cholera, which can lead to death within hours if left untreated. Two important Vibrio cholerae serogroups 01 and 0139 caused periodic epidemic and pandemic outbreaks. Cholera got into Ghana in the 1970s $[1,2]$ and since has remained a serious public health problem in Ghana and many parts of the African continent [3]. Ghana had an unprecedented cholera outbreak in 2014, which progressed into 2015, affecting 28,975 people with 243 deaths. The disease spread to all the 10 Regions of Ghana, reaching 130 out of the 216 districts by the end of 2014 [4]. Cholera diagnosis in the 2014 outbreak in Ghana was based on "OneStep" Rapid, immunochromographic test (SD Bio-line) [5] performed on human faecal specimen, so the biotype, serogroup and

\section{*Correspondence: pfeglo.sms@knust.edu.gh}

Department of Clinical Microbiology, School of Medical Sciences, College of Health Sciences, Kwame Nkrumah University of Science and Technology, Kumasi, Ghana serotype of the $V$. cholerae causing the infection were not known. This study determined the biotype, serogroup, Cholera toxin (CtxAB), Toxin-coregulated pilus (Tcp) genes, SXT constin (conjugable, self-transmissible, integrating element-carrying antibiotic resistance genes), fingerprint and antimicrobial susceptibility patterns of the $V$. cholerae causing the 2014 outbreak in Ghana.

\section{Main text}

Collection of Vibrio isolates

The study was conceptualized in the peak of the cholera outbreak in 2014, but was done between March and May, 2015. There was delay and the cholera outbreak ended due to difficulties in ethical clearance and laboratory logistics acquisition. Regional laboratories were targeted for $V$. cholerae isolates but these laboratories had no stored isolates. The National Public Health Laboratory (NPHRL) in Accra, stored positive rectal swabs after culture in cryo-tubes containing $20 \%$ glycerol in Tryptone soy broth (Oxoid Limited, Basingstoke, UK) at $-80{ }^{\circ} \mathrm{C}$. 
These stored rectal swabs were retrieved and cultured for $V$. cholerae for this study.

\section{Culture of rectal swabs}

Sixty-two rectal swabs taken from NPHRL were cultured on Thiosulfate-citrate-bile salts-sucrose (TCBS) agar (Oxoid Limited, Basingstoke, UK). Forty rectal swabs grew suspected Vibrios and single colonies were subcultured on trypticase soy agar and used for identification and characterization.

\section{V. cholerae identification tests}

Growths on the trypticase soy agar (Oxoid Limited, Basingstoke, UK) tested with cytochrome oxidase. Those positive were tested with polyvalent $\mathrm{O} 1$ antiserum and monovalent Inaba and Ogawa antisera (Denka Seiken Co., Ltd. Tokyo, Japan). Biotyping involved (i) production of beta-haemolysis on sheep blood agar which was observed on $5 \%$ sheep blood agar after overnight incubation. (ii) Susceptibility to polymyxin B was done by placing a 50-unit polymyxin B disk on a seeded Mueller-Hinton agar (Liofilchem s.r.l. Bacteriology products, Italy) and then incubated overnight at $35{ }^{\circ} \mathrm{C}$. The El Tor biotype is usually resistant to this concentration of polymyxin B [6] and (iii) the Voges-Proskauer test positivity was performed by adding the test organism to VogesProskauer broth (Oxoid, Basingstoke, United Kingdom) and incubated at $35{ }^{\circ} \mathrm{C}$ overnight. Then $0.6 \mathrm{~mL}$ of $5 \%$ alpha naphthol was added, followed by $0.2 \mathrm{~mL}$ of $40 \%$ $\mathrm{KOH}$, shaken for $15 \mathrm{~min}$ and observed for a red colour in the top layer in the tube.

\section{Antimicrobial susceptibility testing of the isolates}

Antimicrobial susceptibility of the isolates was determined by the Kirby-Bauer disk diffusion method on Mueller-Hinton agar (Oxoid Limited, Basingstoke, UK) with $E$. coli ATCC 25922 as control. The $V$. cholerae isolates were tested against nine antimicrobials and diameter of zones of inhibition were measured and interpreted according to the guidelines of Clinical and Laboratory Standards Institute (CLSI, 2015) (http://www.clsi.org).

\section{Cholera toxin gene (CtxAB) and toxin coagulated pilus (Tcp) and SXT genes determinations}

DNA was extracted from the $V$. cholerae isolates using spherolyse extraction kit (Hain Lifescience, Germany). The CtxAB and Tcp primer sequences and PCR optimizations were adopted from protocols described [7] and SXT primers and PCR optimizations adopted were also described earlier [8]. All PCR primers were obtained from Intergrated DNA Technologies (USA). PCR was run in a reaction volume of $50 \mu \mathrm{L}$ using the $V$. cholerae DNA template as follows:

\section{Cycling conditions for cholera toxin (CtxAB)}

Initial denaturation-94 ${ }^{\circ} \mathrm{C}$ for $3 \mathrm{~min}$; denaturation $-94{ }^{\circ} \mathrm{C}$ for $1 \mathrm{~min}$; annealing $-78{ }^{\circ} \mathrm{C}$ for $30 \mathrm{~s}$; extension $-72{ }^{\circ} \mathrm{C}$ for $1 \mathrm{~min}$; final extension $72{ }^{\circ} \mathrm{C}$ for $10 \mathrm{~min}$.

\section{Cycling conditions for toxin coregulated pilus (TCP)}

Initial denaturation $-94{ }^{\circ} \mathrm{C}$ for $3 \mathrm{~min}$; denaturation $-94{ }^{\circ} \mathrm{C}$ for $1 \mathrm{~min}$; annealing $-59^{\circ} \mathrm{C}$ for $30 \mathrm{~s}$; extension $-72{ }^{\circ} \mathrm{C}$ for $1 \mathrm{~min}$; final extension $72{ }^{\circ} \mathrm{C}$ for $10 \mathrm{~min}$.

\section{Cycling conditions for SXT gene}

Initial denaturation $-94{ }^{\circ} \mathrm{C}$ for $3 \mathrm{~min}$; denaturation $-94{ }^{\circ} \mathrm{C}$ for $1 \mathrm{~min}$; annealing- $62{ }^{\circ} \mathrm{C}$ for $30 \mathrm{~s}$; extension $-72{ }^{\circ} \mathrm{C}$ for $1 \mathrm{~min}$; final extension $-72^{\circ} \mathrm{C}$ for $10 \mathrm{~min}$.

\section{Separation of amplicons by gel electrophoresis}

The PCR products were stained with ethidium bromide and separated in $1.5 \%$ agarose gel and captured with a Kodak camera (Kodak, Japan).

\section{PFGE determination}

The $V$. Cholerae isolates were inoculated into CareyBlair transport medium and sent by post to the National Institute for Communicable Diseases Division, National Health Laboratory Service, South Africa, for the PFGE. In South Africa, many strains failed to grow when subcultured, but nine strains survived and were characterized by the Pulsed Field Gel Electrophoresis (PFGE). The strains were digested by $S$ fiI restriction enzyme and separated in 1\% Seakem Gold Agarose in CHEF-DR electrophoresis system (Bio-Rad). Salmonella Braenderup (H9812) was used as a control strain.

\section{Data analysis}

Data generated was analyzed with STATA StataCorp LP, USA). Categorical values were expressed as proportions and compared using Chi square tests. $\mathrm{P}$ value $<0.05$ was considered significant.

\section{Results}

A total of 62 rectal swabs were obtained from NPHRLKorle Bu and Komfo-Anokye Teaching Hospital (KATH), out of which $40 \mathrm{~V}$. cholerae were isolated. Most of the isolates being 39 (97.5\%) were obtained from NPHRL, Korle$\mathrm{Bu}$, only one isolate was obtained from KATH, Kumasi. All the 40 isolates were identified to be $V$. cholerae 01 biotype $\mathrm{El}$ Tor, serotype Ogawa, bearing the classical CtxAB, Tcp and SXT genes where they were detected in 39 (97.5\%) of the 40 $V$. cholerae isolated. One isolate from among the NPHRL strains lacked both the CtxAB and Tcp genes. SXT constin found in 39 (97.5\%) of the isolates, also caused resistance to trimethoprim/sulfamethoxazole and 4 (35\%) SXT constin positive isolates were resistant to chloramphenicol. 


\section{Antimicrobial susceptibility}

Antimicrobial susceptibility pattern of the $V$. cholerae isolates was determined. Most of the isolates (i.e. 95\%), were resistant to trimethoprim/sulfamethoxazole, $90 \%$ were resistant to ampicillin and $75 \%$ were resistant to ceftriaxone. The resistance and susceptible proportions of the isolates when compared were statistically significant $(\mathrm{P}=0.001)$ against ampicillin, ceftriaxone and trimethoprim/sulfamethoxazole. Eight (20\%) of the isolates were resistant to ampicillin, chloramphenicol, trimethoprim/ sulfamethoxazole and ceftriaxone, making the isolates multidrug resistant (resistant to $\geq 3$ antibiotics). The multidrug resistance distribution of the isolates show $19(47.5 \%)$ and 8 (20\%) isolates were resistant to 3 and 4 antibiotics respectively. The resistance proportions and multidrug resistance pattern of the isolates are presented in Fig. 1.

PFGE gel produced good fingerprint patterns for eight isolates (except one). These gel patterns were captured into BioNumerics software for dendrogram analysis where they were compared with patterns of $V$. cholerae strains isolated from the African continent in the past. The gel pattern and the dendogram analysis output pattern are presented in Figs. 2 and 3 respectively.

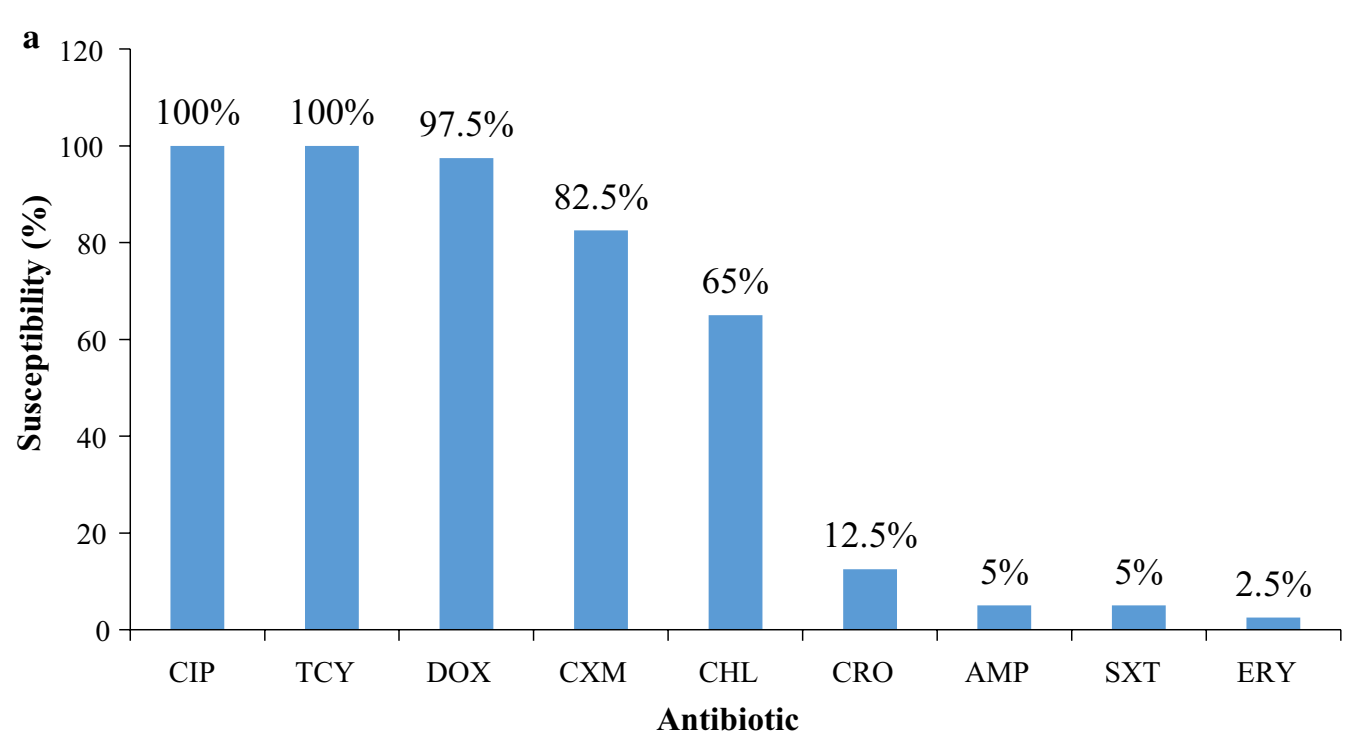

b

\begin{tabular}{lll}
\hline Antibiotics & $\begin{array}{l}\text { No. (\%) of } \\
\text { isolates } \\
\text { resistant }\end{array}$ & $\begin{array}{l}\text { Location from } \\
\text { which isolate } \\
\text { was obtained }\end{array}$ \\
\hline CRO & $1(2.5)$ & NPHRL \\
SXT & $1(2.5)$ & KATH \\
AMP & $1(2.5)$ & NPHRL \\
AMP SXT CRO & $19(47.5)$ & NPHRL \\
AMP SXT CHL & $3(7.5)$ & NPHRL \\
AMP SXT CXM CRO & $3(7.5)$ & NPHRL \\
AMP SXT CHL CRO & $8(20)$ & NPHRL \\
AMP SXT DOX CXM CRO & $1(2.5)$ & NPHRL \\
AMP SXT CHL CXM CRO & $3(7.5)$ & NPHRL \\
\hline
\end{tabular}

Key: $\mathrm{AMP}=$ Ampicillin, $\mathrm{CIP}=$ Ciprofloxacin, $\mathrm{CRO}=$ Ceftriaxone, $\mathrm{CHL}=$ Chloramphenicol, DOX= Doxycycline, CXM = Cefuroxime, NPHRL=National Public Health Laboratory, $\mathrm{KATH}=$ Komfo Anokye Teaching Hospital

Fig. 1 a Antimicrobial susceptibility pattern of Vibrio cholerae isolates of the 2014 outbreak in Ghana. b Multidrug resistance pattern of Vibrio cholerae isolated in Ghana 


\section{Discussion}

In Ghana cholera is endemic and its spread is greatly enhanced by improper food hygiene, poor sanitation, environmental and waste disposal systems [9].

The cholera toxin gene (CtxAB) and toxin coregulated pillus (Tcp) gene are both needed by $V$. cholerae for its pathogenesis in humans [10], which were found in the classical $\mathrm{O} 1$ and the $\mathrm{O} 139$ serogroups initially but not the El Tor strain which caused mild diarrhoeal disease that mimicked cholera. The El Tor strains in India and Africa have now acquired the toxin genes by horizontal conjugal transfer [10] and therefore cause classical cholera. The V. cholerae strains isolated in the 2014 outbreak were El Tor strains but caused severe cholera and a large outbreak. The Ghana strains acquired the classical cholera toxin genes and now behaved as the classical 01/0139 biotypes [11, 12] and such El Tor biotype lineage with CtxAB genes is associated with increased virulence and increased cholera toxin production with severe disease [13]. It is unclear whether this El Tor lineage with CtxAB gene in addition to the Tcp have given the 2014 cholera strains from Ghana an increased virulence and this needs to be investigated in other studies.

Acquisition of antibiotic resistance by $V$. cholerae isolates is an important clinical phenomenon with increased risk of treatment failure and patients' prolonged hospital stays. Though mainstay of cholera treatment is fluid and electrolyte replacement [14], antibiotic administration shortens period of diarrhoea and reduces Vibrio excretion in stool. Emerged Vibrio resistotypes have acquired SXT constin [15], which are mobilizable plasmids make many isolates multidrug resistant [16] and it is spread by open defaecation as practiced in Ghana. This study detected 95\% isolates carry SXT constin with resultant resistance to ampicillin (95\%) and chloramphenicol (95\%). Widespread dissemination of SXT clone in the Ghanaian strains heightens growing concern over multidrug resistant Vibrio strains [16-18]. V. cholerae infection may become difficult to treat, infected individuals may harbour the organisms longer and excrete them in the environment, while Vibrios may serve as SXT constin reservoirs [10] for dissemination.

PFGE results in this present study show more than one strain type circulated in the cholera outbreak. V. cholerae are phylogenetically diverse with equally diverse virulent factors [10]. Eight Ghana strains showed similar and indistinguishable PFGE patterns, except one strain with different PFGE pattern, meaning more than one strain type caused the 2014 outbreak as seen in other studies where different clones were found in individual patients and outbreaks [19] due to phage and plasmids gain and loss. The eight strains with good PFGE patterns were committed to BioNumeric software for dendogram analysis, and were seen to share patterns previously seen in isolates from DR Congo, Togo, Cameroun and Ivory Coast.

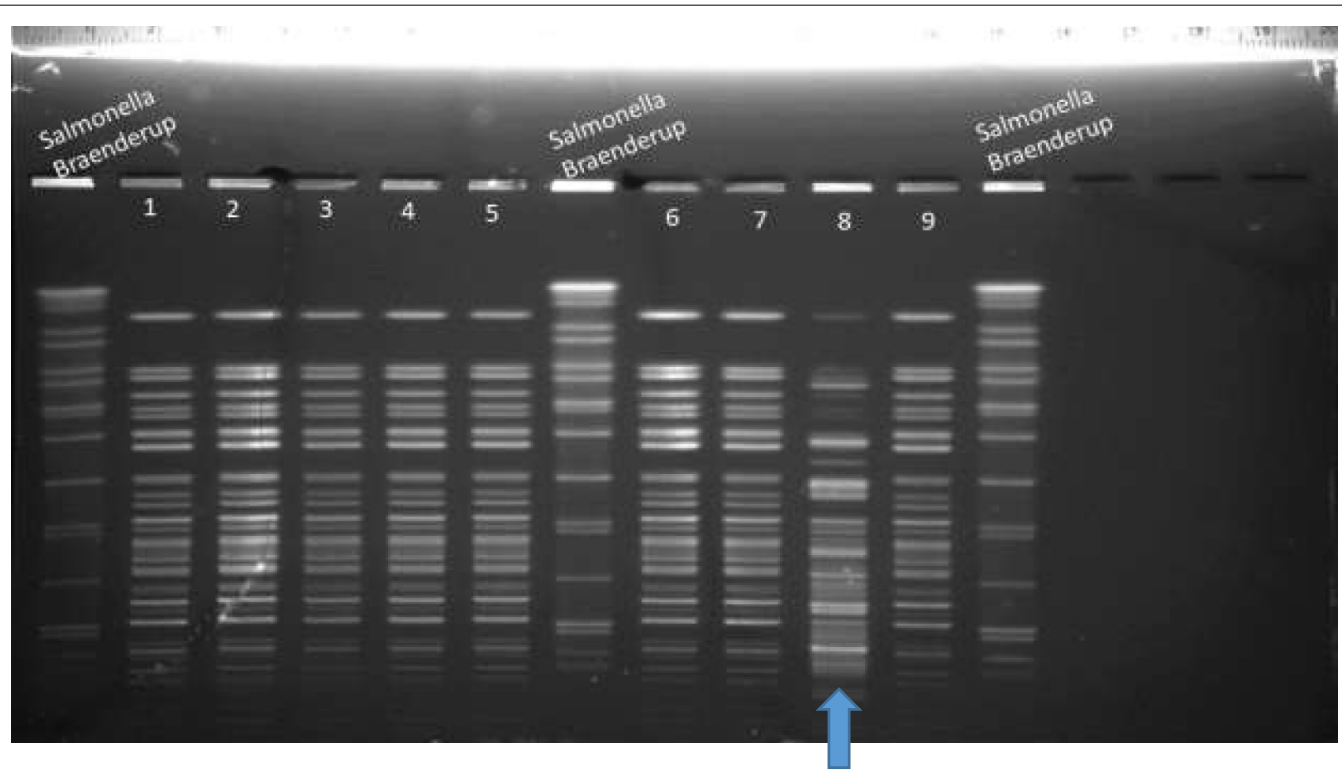

Lanes 1, 2, 3, 4, 5, 6, 7, 8, 9 are test strains. Lane 8 (arrowed) showed different pattern indicating it is a different strain

Fig. 2 PFGE on V. cholerae O1 isolated from 2014 cholera outbreak in Ghana 


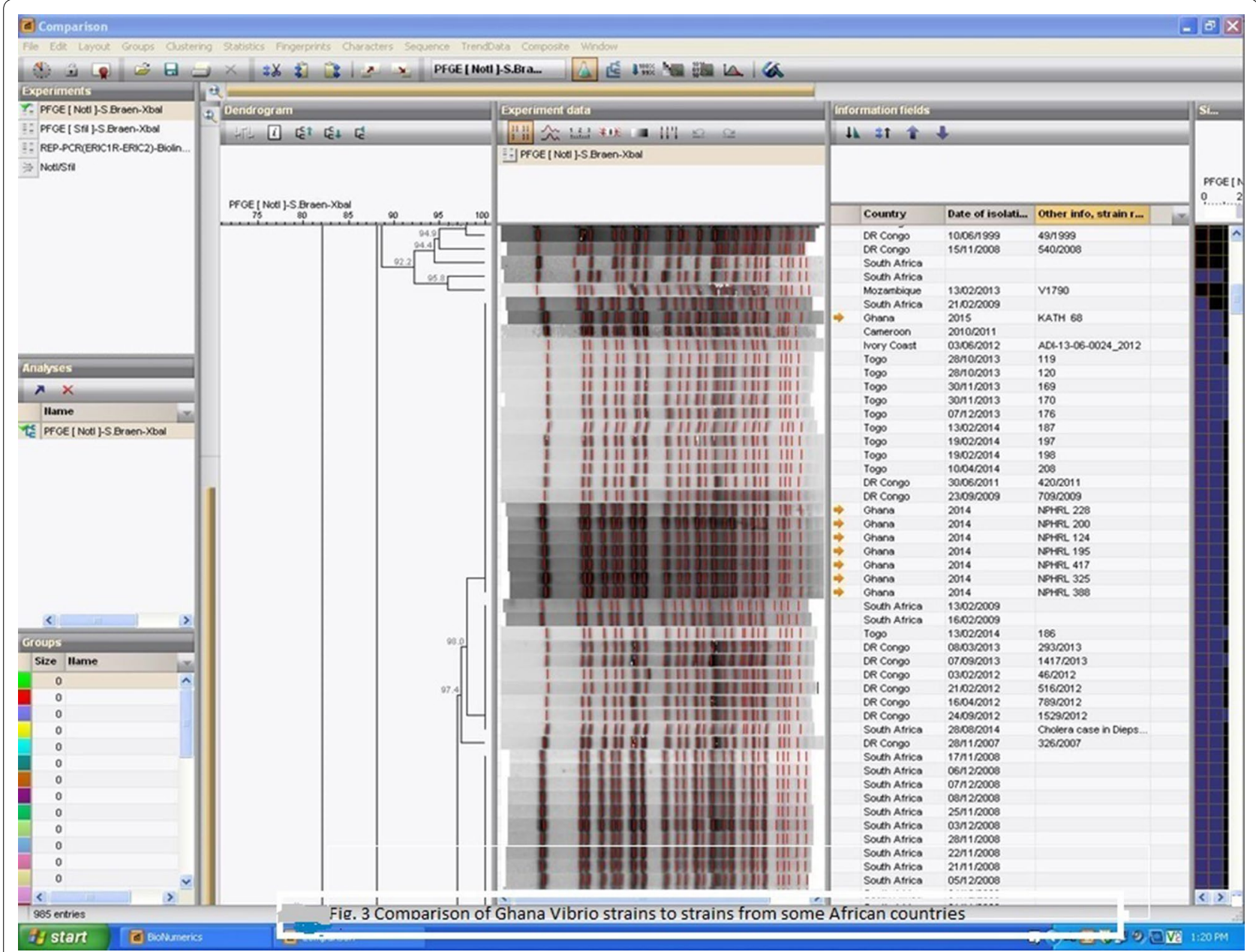

Fig. 3 Comparison of Ghana Vibrio strains to strains from some African countries

This study reports that the 2014 cholera outbreak in Ghana was caused by $V$. cholerae biotype El Tor, O1 serogroup, serotype Ogawa, bearing CtxAB and Tcp genes and SXT genes and are similar to those already known circulating in Africa.

\section{Limitations}

Lack of funds delayed the study, so stored samples were used, which also caused delay in shipping the isolates to South Africa leading their death, leaving only nine survivors for PFGE fingerprinting. A study involving more strains and transcriptional gene regulators such as ToxR in the Ghanaian V. cholerae is suggested.

\section{Abbreviations}

CtxAB: cholera toxin encoding operon ; Tcp : toxin-coregulated pilus; SXT: conjugative, self-transmissible integrating element; PFGE: pulsed field gel electrophoresis; DR : Democratic Republic of Congo.

\section{Authors' contributions}

PF conceptualized, designed, analyzed data and prepared the manuscript for publication, MS did sample retrieval from the NPHRL and also cultured the samples. Both authors read and approved the final manuscript.

\section{Acknowledgements}

The researchers are grateful to Dr. Anthony Smith for the PFGE analysis; He is a Senior Scientist \& Coordinator for PulseNet Africa, Centre for Enteric Diseases (Bacteriology Division), National Institute for Communicable Diseases Division in the National Health Laboratory Service, South Africa.

\section{Competing interests}

The authors declare that they have no competing interests.

\section{Availability of data and materials}

The dataset used and/or analyzed during the current study is available from the corresponding author on request.

\section{Consent for publication}

Not applicable.

\section{Ethics approval and consent to publish}

Ethical approval (Ref No. CHRPE/030/15) was obtained from the Joint Committee on Human Research, Publication and Ethics of School of Medical Sciences 
and Komfo Anokye Teaching Hospital. Consent to publish from individual patients was not applicable. The work involved analysis of stored samples which were not traceable to individual patients.

\section{Funding}

There was no official funding for the study. Materials and other resources were acquired from the principal author's personal income.

\section{Publisher's Note}

Springer Nature remains neutral with regard to jurisdictional claims in published maps and institutional affiliations.

Received: 28 July 2017 Accepted: 9 November 2017

Published online: 18 January 2018

\section{References}

1. Goodgame RW, Greenough WB. Cholera in Africa: a message for the West. Ann Intern Med. 1975;82(1):101-6.

2. Kwofie KM. A spatio-temporal analysis of cholera diffusion in Western Africa. Econ Geogr. 1976:52(2):127-35.

3. Mengel MA, Delrieu I, Heyerdahl L, Gessner BD. Cholera outbreaks in Africa. In: Nair G, Takeda Y, editors. Cholera outbreaks. Current topics in microbiology and immunology, vol 379. Berlin, Heidelberg: Springer; 2014. p. 117-44

4. WHO. Country office Ghana. Cholera situation report on cholera outbreak in Ghana as of 30 August 2015 (Week 35). 2015.

5. Nato F, Boutonnier A, Rajerison M, Grosjean P, Dartevelle S, Guénolé A Bhuiyan NA, Sack DA, Nair GB, Fournier JM, et al. One-step immunochromatographic dipstick tests for rapid detection of Vibrio cholerae $\mathrm{O} 1$ and 0139 in stool samples. Clin Diagn Lab Immunol. 2003;10(3):476-8.

6. World Health Organization, Centers for Disease Control and Prevention. Laboratory methods for the diagnosis of epidemic dysentery and cholera. Geneva: World Health Organization; 1999.

7. Menezes FGRD, Neves SDS, Sousa OVD, Vila-Nova CMVM, Maggioni R, Theophilo GND, Hofer E, Vieira RHSDF. Detection of virulence genes in environmental strains of Vibrio cholerae from estuaries in Northeastern Brazil. Revista do Instituto de Medicina Tropical de São Paulo. 2014:56(5):427-32.
8. Ramachandran D, Bhanumathi R, Singh DV. Multiplex PCR for detection of antibiotic resistance genes and the SXT element: application in the characterization of Vibrio cholerae. J Med Microbiol. 2007:56(3):346-51.

9. Ofori-Adjei D, Koram K. Of cholera and Ebola virus disease in Ghana. Ghana Med J. 2014:48(3):120.

10. Herrington DA, Hall RH, Losonsky G, Mekalanos JJ, Taylor RK, Levine MM Toxin, toxin-coregulated pili, and the toxR regulon are essential for Vibrio cholerae pathogenesis in humans. J Exp Med. 1988;168(4):1487-92.

11. Mutreja A, Kim DW, Thomson NR, Connor TR, Lee JH, Kariuki S, Croucher NJ, Choi SY, Harris SR, Lebens M. Evidence for several waves of global transmission in the seventh cholera pandemic. Nature. 2011;477(7365):462-5.

12. Raychoudhuri A, Patra T, Ghosh K, Ramamurthy T, Nandy RK, Takeda Y, Nair GB, Mukhopadhyay AK. Classical ctxB in Vibrio cholerae O1, Kolkata, India. Emerg Infect Dis. 2009;15(1):131-2.

13. Li F, Du P, Li B, Ke C, Chen A, Chen J, Zhou H, Li J, Morris JG, Kan B. Distribution of virulence-associated genes and genetic relationships in non-01/0139 Vibrio cholerae aquatic isolates from China. Appl Environ Microbiol. 2014;80(16):4987-92.

14. Kobari K, Uylangco C, Vasco J, Takahira Y, Shimizu N. Observations on cholera treated orally and intravenously with antibiotics: with particular reference to the number of vibrios excreted in the stool. Bull World Health Organ. 1967;37(5):751.

15. Toma C, Nakasone N, Song T, Iwanaga M. Vibrio cholerae SXT element, Laos. Emerg Infect Dis. 2005;11:346-7.

16. Igbinosa EO. Detection and antimicrobial resistance of Vibrio isolates in aquaculture environments: implications for public health. Microb Drug Resist. 2016;22(3):238-45.

17. Gupta PK, Pant ND, Bhandari R, Shrestha P. Cholera outbreak caused by drug resistant Vibrio cholerae serogroup $\mathrm{O} 1$ biotype ElTor serotype Ogawa in Nepal; a cross-sectional study. Antimicrob Resist Infect Control. 2016;5(1):1

18. Das S, Choudhry S, Saha R, Ramachandran VG, Kaur K, Sarkar BL. Emergence of multiple drug resistance Vibrio cholerae 01 in East Delhi. J Infect Dev Ctries. 2011;5:294-8.

19. Levade I, Terrat Y, Leducq JB, Weil AA, Mayo-Smith LM, Chowdhury F, Khan Al, Boncy J, Buteau J, Ivers LC, Ryan ET. Vibrio cholerae genomic diversity within and between patients. bioRxiv. 2017:169292. https://doi. org/10.1101/169292

\section{Submit your next manuscript to BioMed Central and we will help you at every step:}

- We accept pre-submission inquiries

- Our selector tool helps you to find the most relevant journal

- We provide round the clock customer support

- Convenient online submission

- Thorough peer review

- Inclusion in PubMed and all major indexing services

- Maximum visibility for your research

Submit your manuscript at www.biomedcentral com/submit
BioMed Central 